\title{
Dpy-19 like 3-mediated $C$-mannosylation and expression levels of RPE-spondin in human tumor cell lines
}

\author{
SHOHEI MORISHITA ${ }^{1}$, TAKEHIRO SUZUKI ${ }^{2}$, YUKI NIWA ${ }^{1}$, NAOSHI DOHMAE $^{2}$ and SIRO SIMIZU $^{1}$ \\ ${ }^{1}$ Department of Applied Chemistry, Faculty of Science and Technology, Keio University, Yokohama, Kanagawa 223-8522; \\ ${ }^{2}$ Biomolecular Characterization Unit, RIKEN Center for Sustainable Resource Science, Wako, Saitama 351-0198, Japan
}

Received February 18, 2017; Accepted May 11, 2017

DOI: $10.3892 / 01.2017 .6465$

\begin{abstract}
C$-mannosylation is a unique type of protein glycosylation with a mannose attached to the tryptophan residue via the $C$ - $C$ linkage. Our previous study revealed that dpy-19 like 3 (DPY19L3) acts as a $C$-mannosyltransferase in human cells. The present study hypothesized that RPE-spondin (RPESP) may be a substrate protein of DPY19L3-mediated $C$-mannosylation. RPESP has unknown biological functions and has two putative $C$-mannosylation sites at the $\mathrm{W}^{80}$ and $\mathrm{W}^{83}$ residues; however, to the best of our knowledge, $C$-mannosylation of RPESP has not previously been investigated. The present study suggested that RPESP is $C$-mannosylated at $\mathrm{W}^{80}$ and $\mathrm{W}^{83}$ in human cells, whereas gain-of-function experiments using $\mathrm{S} 2$ cells revealed that human DPY19L3 catalyzed the $C$-mannosylation of RPESP at $\mathrm{W}^{83}$ but not $\mathrm{W}^{80}$, which suggested substrate specificity. In addition, the present study detected mRNA expression levels of RPESP in various types of cancer cell lines and high expression levels of RPESP were revealed in certain colorectal cancer cell lines, suggesting that RPESP may have an association with the malignancy of colorectal cancers.
\end{abstract}

\section{Introduction}

Glycosylation, one of the post-translational modifications, commonly regulates protein stability, folding and secretion (1-3). Certain types of glycosylation exist, including $\mathrm{N}$-linked and $O$-linked glycosylations, $\mathrm{C}$-mannosylation, and the formation

Correspondence to: Professor Siro Simizu, Department of Applied Chemistry, Faculty of Science and Technology, Keio University, 3-14-1 Hiyoshi, Kohoku, Yokohama, Kanagawa 223-8522, Japan

E-mail: simizu@applc.keio.ac.jp

Abbreviations: TSR-1, thrombospondin type-1 repeat; Rspo, R-spondin; RPESP, RPE-spondin; SMB, somatomedin B; DMEM, Dulbecco's modified Eagle's medium; FBS, fetal bovine serum; CBB, Coomassie Brilliant Blue; LC-MS, liquid chromatography-mass spectrometry; ER, endoplasmic reticulum

Key words: C-mannosylation, $C$-mannosyltransferase, Dpy-19 like 3, glycobiology, mass spectrometry, RPE-spondin of glycosylphosphatidylinositol anchors. $C$-mannosylation is a unique type of glycosylation in which $\alpha$-D-mannose is attached directly to the indole $\mathrm{C}_{2}$ carbon atom of a tryptophan residue via a $C$ - $C$ linkage $(4,5) . C$-mannosylation occurs at the first tryptophan residue in the consensus sequence $\mathrm{W}-\mathrm{X}-\mathrm{X}-\mathrm{W} / \mathrm{C}$ (X represents any amino acid) (6). Certain $C$-mannosylated proteins, including ribonuclease 2 (7), interleukin-12 (8), properdin (9) and mindin (10), have been identified; however, the biological roles of $C$-mannosylation remain unclear. A previous study reported that Caenorhabditis elegans (C. elegans) dpy-19 is the $C$-mannosyltransferase for the thrombospondin type-1 repeat (TSR-1)-derived peptide (11) and that human dpy-19 like 3 (DPY19L3), one of the homologs of C. elegans dpy-19, catalyzes $C$-mannosylation of R-spondin (Rspo) 1 at the $\mathrm{W}^{156}$ residue (12).

RPE-spondin (RPESP) is a protein that has unknown functions and exists in the aorta extracellular matrix $(13,14)$. RPESP has certain domains: An N-terminal signal peptide toward the secretory pathway, followed by a somatomedin B (SMB) domain and TSR-1. Specific proteins containing the SMB domain have been reported to bind plasminogen activator inhibitor-1 and ectonucleotide pyrophosphatase/phosphodiesterase 1 (15-18); however, the physiological functions of its association remain unclear. In the TSR-1 domain, RPESP has two putative $C$-mannosylation sites, the $\mathrm{W}^{80}$ and $\mathrm{W}^{83}$ residues. Previously, it was demonstrated that $C$-mannosylation of TSR-1 in Rspo1 and Rspo3 regulates these functions $(12,19)$. The present study focused on RPESP protein and examined the existence of $C$-mannosylation in RPESP. The results suggested that RPESP is $C$-mannosylated at both prediction sites and that DPY19L3 catalyzes $C$-mannosylation of RPESP at $\mathrm{W}^{83}$ specifically. Therefore, it was indicated that DPY19L3 has substrate specificity and that $C$-mannosylation at $\mathrm{W}^{80}$ is catalyzed by an unidentified $C$-mannosyltransferase. Furthermore, the present study demonstrated that the expression of RPESP was observed in certain human tumor cell lines, suggesting the malignant roles of RPESP in tumorigenesis.

\section{Materials and methods}

Cell culture. Human HT1080 (JCRB Cell Bank, Osaka, Japan) fibrosarcoma, A549 (RIKEN BioResource Center, Tsukuba, Japan) non-small-cell lung cancer, HepG2 (RIKEN BioResource Center) hepatocellular cancer, HT29 [American 
Type Culture Collection (ATCC), Manassas, VA, USA] colon cancer and WM266-4 (ATCC) melanoma cell lines were cultured in Dulbecco's modified Eagle's medium (DMEM; Nissui, Tokyo, Japan) supplemented with $10 \%(\mathrm{v} / \mathrm{v})$ fetal bovine serum (FBS; BioWest S.A.S, Nuaillé, France), $100 \mathrm{U} / \mathrm{ml}$ penicillin $\mathrm{G}, 100 \mathrm{mg} / 1$ kanamycin, $600 \mathrm{mg} / \mathrm{l} \mathrm{L}$-glutamine, and $2.25 \mathrm{~g} / 1 \mathrm{NaHCO}_{3}$ at $37^{\circ} \mathrm{C}$ in a humidified incubator with $5 \% \mathrm{CO}_{2}$. Human ES2 (which was kindly donated by the Department of Obstetrics and Gynecology, Keio University School of Medicine, Tokyo, Japan) ovarian cancer and HCT116 (RIKEN BioResource Center) colon cancer cell lines were cultured in DMEM supplemented with $10 \%(\mathrm{v} / \mathrm{v})$ heat-inactivated FBS, $100 \mathrm{U} / \mathrm{ml}$ penicillin $\mathrm{G}, 100 \mathrm{mg} / \mathrm{l} \mathrm{kana-}$ mycin, $600 \mathrm{mg} / \mathrm{l} \mathrm{L}$-glutamine, and $2.25 \mathrm{~g} / 1 \mathrm{NaHCO}_{3}$ at $37^{\circ} \mathrm{C}$ in a humidified incubator with $5 \% \mathrm{CO}_{2}$. Human COLO 205, CW-2 and LoVo colon cancer cell lines (RIKEN BioResource Center) were cultured in RPMI-1640 (Nissui) supplemented with $10 \%$ (v/v) FBS, $100 \mathrm{U} / \mathrm{ml}$ penicillin G, $100 \mathrm{mg} / \mathrm{l} \mathrm{kana-}$ mycin, $300 \mathrm{mg} / \mathrm{l} \mathrm{L}$-glutamine, and $2.25 \mathrm{~g} / 1 \mathrm{NaHCO}_{3}$ at $37^{\circ} \mathrm{C}$ in a humidified incubator with $5 \% \mathrm{CO}_{2}$. The human Jurkat (ATCC) acute leukemia cell line was cultured in RPMI-1640 supplemented with $10 \%(\mathrm{v} / \mathrm{v})$ heat-inactivated FBS, $100 \mathrm{U} / \mathrm{ml}$ penicillin G, $100 \mathrm{mg} / 1$ kanamycin, $300 \mathrm{mg} / \mathrm{l} \mathrm{L}$-glutamine, and $2.25 \mathrm{~g} / 1 \mathrm{NaHCO}_{3}$ at $37^{\circ} \mathrm{C}$ in a humidified incubator with $5 \% \mathrm{CO}_{2}$. The $\mathrm{S} 2$ Drosophila melanogaster embryonic cell line (RIKEN BioResource Center) was cultured in Schneider's Drosophila medium (Thermo Fisher Scientific, Inc., Waltham, MA, USA), supplemented with $10 \%(\mathrm{v} / \mathrm{v})$ heat-inactivated FBS, $100 \mathrm{U} / \mathrm{ml}$ penicillin $\mathrm{G}$ and $100 \mathrm{mg} / \mathrm{l}$ kanamycin at $25^{\circ} \mathrm{C}$.

Plasmid construction. The synthetic DNA encoding C-terminally Myc-His ${ }_{6}$-tagged human RPESP, optimized to the human codon and introduced with $\mathrm{N}$-terminal $\mathrm{XhoI}$ and C-terminal NotI restriction enzyme sites, respectively, was purchased from Thermo Fisher Scientific, Inc. The synthetic DNA was cloned into the XhoI/NotI restriction sites of pCI-neo vector (Promega Corporation, Madison, WI, USA). For expression in S2 cells, C-terminal Myc-His 6 -tagged RPESP cDNA was amplified by polymerase chain reaction (PCR) from pCI-neo-RPESP-Myc-His ${ }_{6}$ using PrimeSTAR ${ }^{\circledR}$ Max DNA Polymerase (Takara Bio, Inc., Otsu, Japan) according to the manufacturer's protocol. The sequences of the primers used were as follows: Forward, 5'-TTTTAGATCTGGATGTGC CGAAGCCGGCAGAT-3' (Eurofins Genomics, Ebersberg, Germany) and reverse, 5'-TTTTACGCGTCTAATGGTGAT GGTGATGAT-3' (Thermo Fisher Scientific, Inc.). The reaction was conducted in a $\mathrm{C} 1000^{\mathrm{TM}}$ thermal cycler (Bio-Rad Laboratories, Inc., Hercules, CA, USA), and the cycling conditions were as follows: 30 cycles at $98^{\circ} \mathrm{C}$ for $10 \mathrm{sec}, 55^{\circ} \mathrm{C}$ for $5 \mathrm{sec}$ and $72^{\circ} \mathrm{C}$ for $5 \mathrm{sec}$. Subsequently, the RPESP-Myc-His ${ }_{6}$ cDNA was subcloned into the $B g l \mathrm{II} / \mathrm{Mlu \textrm {I }}$ restriction sites of pMT-PURO (RIKEN BioResource Center) (20), resulting in

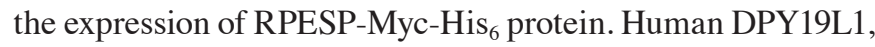
DPY19L2, DPY19L3 and DPY19L4 cDNAs, which were subcloned into pIZ/V5-his vectors (Thermo Fisher Scientific, Inc.), were constructed previously (12).

Establishment of an RPESP-overexpressing cell line. The permanent cell line expressing wild-type RPESP-Myc-His ${ }_{6}$ was established by transfecting the vectors using Lipofectamine ${ }^{\circledR}$
LTX (Thermo Fisher Scientific, Inc.) into HT1080 cells for $24 \mathrm{~h}$ at $37^{\circ} \mathrm{C}$, followed by $400 \mu \mathrm{g} / \mathrm{ml} \mathrm{G} 418$ (Wako Pure Chemical Pure Industries, Ltd., Osaka, Japan) selection. The

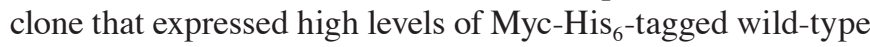
RPESP was designated HT1080-RPESP-MH. The cells that were transfected with pCI-neo were designated HT1080-neo as control (21).

Western blotting. Western blot analysis was performed according to a previously described method with slight modification (22-26). HT1080-neo (control) and HT1080-RPESP-MH cells were cultured for $24 \mathrm{~h}$ at $37^{\circ} \mathrm{C}$ and lysed in a lysis buffer [50 mM Tris- $\mathrm{HCl}$ (pH 7.5), $150 \mathrm{mM} \mathrm{NaCl}, 0.1 \%$ (w/v) SDS, $1 \%(\mathrm{v} / \mathrm{v})$ Triton X-100, $1 \%(\mathrm{w} / \mathrm{v})$ sodium deoxycholate and $1 \mathrm{mM}$ phenylmethylsulfonyl fluoride] with sonication $(20 \mathrm{kHz}$, $50 \mathrm{~W}, 10 \mathrm{sec}$, twice) in an ultrasonic homogenizer (UH-50; SMT Co., Ltd., Tokyo, Japan) at $4^{\circ} \mathrm{C}$. The lysates were centrifuged at $16,100 \mathrm{xg}$ for $10 \mathrm{~min}$ at $4^{\circ} \mathrm{C}$ and the amount of protein in each lysate was evaluated by staining with Coomassie Brilliant Blue (CBB) G-250 (Bio-Rad Laboratories, Inc.). A loading buffer [ $350 \mathrm{mM}$ Tris- $\mathrm{HCl}$ (pH 6.8), 30\% (w/v) glycerol, $0.012 \%(\mathrm{w} / \mathrm{v})$ bromophenol blue, $6 \%(\mathrm{w} / \mathrm{v})$ SDS and 30\% (v/v) 2-mercaptoethanol] was added to each lysate, which was subsequently boiled for $3 \mathrm{~min}$. Proteins (15 $\mu \mathrm{g}$ per lane) were loaded and electrophoresed on $12.5 \%$ SDS-polyacrylamide gels. The proteins were transferred to polyvinylidene difluoride membranes. Membranes were blocked with TBS-Tween-20 [TBST; $20 \mathrm{mM}$ Tris- $\mathrm{HCl}$ (pH 7.6), $137 \mathrm{mM} \mathrm{NaCl}$ and $0.1 \%$ (v/v) Tween-20] containing 5\% Difco ${ }^{\mathrm{TM}}$ skim milk (cat. no. 232100; BD Biosciences, Franklin Lakes, NJ, USA) for $30 \mathrm{~min}$ at room temperature, and immunoblotted with anti-c-myc [dilution, 1:50 (9E10 hybridoma cultured supernatant in TBST containing 5\% Difco ${ }^{\mathrm{TM}}$ skim milk; cat. no. 9E10 hybridoma; Developmental Studies Hybridoma Bank, Iowa City, IA, USA) antibody for $1 \mathrm{~h}$ at room temperature. Subsequently, membranes were incubated with TBST containing 5\% Difco ${ }^{\mathrm{TM}}$ skim milk secondary horseradish peroxidase (HRP)-conjugated sheep polyclonal anti-mouse IgG (dilution, 1:3,000; cat. no. NA931V; GE Healthcare Life Sciences, Little Chalfont, UK) for $1 \mathrm{~h}$ at room temperature. Detection was performed using Immobilon Western Chemiluminescent HRP substrates (EMD Millipore, Billerica, MA, USA) on an ImageQuant LAS4000mini (GE Healthcare Life Sciences). To detect all loading control proteins, the membrane was stained by Coomassie brilliant blue solution at room temperature for $5 \mathrm{~min}$ (27). Western blotting was conducted in three independent experiments.

Purification of recombinant wild-type RPESP from whole-cell lysate. HT1080-RPESP-MH cells were lysed using the aforementioned lysis buffer, and the cell lysate was used for purification. Initially, solid ammonium sulfate was slowly added with agitation of the lysate preparations $(125 \mathrm{ml})$ until $30 \%$ saturation was achieved. The $\mathrm{pH}$ of the lysate was maintained at $\mathrm{pH} 8.0$ by dropwise addition of $5 \mathrm{~N} \mathrm{NaOH}$ and the mixture was incubated on ice for $30 \mathrm{~min}$. Subsequently, the precipitates were separated by centrifugation at $16,100 \mathrm{x} \mathrm{g}$ for $30 \mathrm{~min}$ at $4^{\circ} \mathrm{C}$ and the supernatant was collected. Solid ammonium sulfate was slowly added to the supernatant until $60 \%$ saturation was achieved and the solution was preserved on ice for another $30 \mathrm{~min}$ prior to centrifugation at $16,100 \mathrm{x} \mathrm{g}$ for 
$30 \mathrm{~min}$ at $4^{\circ} \mathrm{C}$. The precipitates were collected and dissolved in a small volume $(\sim 2 \mathrm{ml})$ of PBS, and added to $1 \%(\mathrm{w} / \mathrm{v})$ SDS. The mixture was sonicated $(20 \mathrm{kHz}, 50 \mathrm{~W}, 15 \mathrm{sec}$, 15 times) at $4^{\circ} \mathrm{C}$ and centrifuged at $16,100 \mathrm{x} \mathrm{g}$ for $15 \mathrm{~min}$ at $4^{\circ} \mathrm{C}$. The supernatant was subjected to buffer exchange with PBS using PD-10 Desalting Columns (GE Healthcare Life Sciences). Following the addition of $8 \mathrm{M}$ urea, the mixture was incubated with Ni-NTA agarose (Qiagen $\mathrm{GmbH}$, Hilden, Germany) for $2 \mathrm{~h}$ at $4^{\circ} \mathrm{C}$. The Ni-NTA agarose was washed three times with buffer A $(900 \mathrm{mM} \mathrm{NaCl}, 2.7 \mathrm{mM} \mathrm{KCl}$, $10 \mathrm{mM} \mathrm{Na}_{2} \mathrm{HPO}_{4}, 1.8 \mathrm{mM} \mathrm{KH}_{2} \mathrm{PO}_{4}$ and $20 \mathrm{mM}$ imidazole) and Ni-NTA agarose-bound RPESP was eluted with $100 \mu \mathrm{l}$ of $500 \mathrm{mM}$ imidazole. Eluates (20 $\mu \mathrm{l}$ per lane) were loaded and electrophoresed on a $12.5 \%$ SDS-PAGE and the protein bands were visualized using CBB staining for $1 \mathrm{~h}$ at room temperature. The stained gel was scanned with CanoScan LiDE 200 (Canon, Tokyo, Japan) using MP Navigator EX software (Ver. 2.0.7; Canon).

Liquid chromatography-mass spectrometry (LC-MS). In order to determine the $C$-mannosylation sites, the present study used the ultra-sensitive 'Q-Exactive' nano LC-MS/MS system (28). Purified RPESP samples were subjected to $12.5 \%$ SDS-PAGE. Following CBB staining for $1 \mathrm{~h}$ at room temperature, the visible band was excised and de-stained. The band was reduced using $50 \mathrm{mM}$ dithiothreitol (Wako Pure Chemical Industries, Ltd.) at $37^{\circ} \mathrm{C}$ for $2 \mathrm{~h}$, followed by carboxymethylated with $100 \mathrm{mM}$ iodoacetate (Sigma-Aldrich; Merck KGaA) at $25^{\circ} \mathrm{C}$ for $30 \mathrm{~min}$. In-gel digestion was performed using trypsin (TPCK-treated; Worthington Biochemical Corporation, Lakewood, NJ, USA) at $37^{\circ} \mathrm{C}$ for $12 \mathrm{~h}$. The digestion mixture was separated on a nanoflow LC (Easy nLC; Thermo Fisher Scientific, Inc.) using a nano-electrospray ionization spray column (NTCC analytical C18 column, $\varphi 75 \mu \mathrm{m}$ x100 mm, $3 \mu \mathrm{m}$; Nikkyo Technos Co., Ltd., Tokyo, Japan) with a linear gradient of 5-60\% buffer B (100\% acetonitrile and $0.1 \%$ formic acid) at a flow rate of $300 \mathrm{nl} / \mathrm{min}$ over $10 \mathrm{~min}$ and subjected on-line to a Q-Exactive mass spectrometer (Thermo Fisher Scientific, Inc.), which was equipped with a nanospray ion source. MS and MS/MS data were acquired using the data-dependent TOP10 method (28). Obtained MS/MS data were searched against an in-house database, including the RPESP sequence, using the MASCOT program (Matrix Science, Inc., Boston, MA) with variable modifications: Gln $\rightarrow$ pyro-Glu (N-term Q), oxidation (M), propionamide $(\mathrm{C})$ and Hex $(\mathrm{W}) . \mathrm{MS} / \mathrm{MS}$ chromatograms and spectra were acquired using the targeted MS/MS method (28).

Purification of RPESP from S2 cells. S2 cells were plated on $100 \mathrm{~mm}$ dishes and transfected with pMT-RPESP-MH and pIZ-DPY19L1, pIZ-DPY19L2, pIZ-DPY19L3, pIZ-DPY19L4 or $\mathrm{pIZ}$ as a control using transIT-Insect Transfection reagent (Mirus Bio, LLC, Madison, WI, USA) at $25^{\circ} \mathrm{C}$. Following $24 \mathrm{~h}$, the cells were washed and cultured in Schneider's Drosophila medium at $25^{\circ} \mathrm{C}$ with $700 \mu \mathrm{M} \mathrm{CuSO}_{4}$ to induce RPESP expression. Following $48 \mathrm{~h}$ of induction, the cells were lysed in $1 \mathrm{ml}$ of the aforementioned lysis buffer with sonication $(20 \mathrm{kHz}$, $50 \mathrm{~W}, 15 \mathrm{sec}$, four times) at $4^{\circ} \mathrm{C}$ and $50 \mu \mathrm{l}$ of Ni-NTA agarose was added to the lysates. After $2 \mathrm{~h}, \mathrm{Ni}-\mathrm{NTA}$ agarose-bound RPESP was eluted with $100 \mu 1$ of $500 \mathrm{mM}$ imidazole. Eluates (20 $\mu \mathrm{l}$ per lane) were loaded and electrophoresed on $12.5 \%$
SDS-polyacrylamide gels. The protein bands were visualized using $\mathrm{CBB}$ for $1 \mathrm{~h}$ at room temperature and the visible band was excised and de-stained. The samples were treated with $\mathrm{N}$-(iodoethyl)-trifluoroacetamide for cysteine-aminoethylation, followed by LC-MS analysis, as aforementioned.

Reverse transcription-semi-quantitative PCR (RT-sqPCR). Reverse transcribed cDNAs of A549, ES2, HepG2, HT1080, HT29, Jurkat, LNCaP, WM266-4, COLO 205, CW-2, HCT116 and LoVo human cancer cell lines were used for PCR amplification using Quick Taq HS Dye mix (Toyobo, Co., Ltd., Osaka, Japan), according to the manufacturer's protocol. The sequences of the primers used (synthesized by Thermo Fisher Scientific, Inc.) for RT-sqPCR were as follows: RPESP forward, 5'-GACAGGGTCTACGGGACGTGTTTC-3' and reverse, 5'-TGCAGAGGTAGTTATAAAGGCAG-3'; $\beta$-actin forward, 5'-CTTCGAGCACGAGATGGCCA-3' and reverse, 5'-CCAGACAGCACTGTGTTGGC-3'. The cycling conditions were as follows: RPESP, $94^{\circ} \mathrm{C}$ for $2 \mathrm{~min}$, followed by 25 cycles at $94^{\circ} \mathrm{C}$ for $30 \mathrm{sec}, 60^{\circ} \mathrm{C}$ for $30 \mathrm{sec}$ and $68^{\circ} \mathrm{C}$ for $30 \mathrm{sec} ; \beta$-actin, $94^{\circ} \mathrm{C}$ for $2 \mathrm{~min}$, followed by 20 cycles at $94^{\circ} \mathrm{C}$ for $30 \mathrm{sec}, 58^{\circ} \mathrm{C}$ for $30 \mathrm{sec}$ and $68^{\circ} \mathrm{C}$ for $30 \mathrm{sec}$. $\beta$-actin was used for the loading control. PCR products were electrophoresed on $2 \%$ agarose gels, stained with ethidium bromide for $10 \mathrm{~min}$ at room temperature and visualized using an ultraviolet illuminator. The expression levels of transfected DPY19L1-L4 genes in S2 cells were normalized to GAPDH and confirmed according to a previously described method (12). RT-sqPCR was conducted in three independent experiments.

\section{Results}

RPESP is C-mannosylated in cells. The amino acid sequence of human RPESP contains two possible $C$-mannosylation sites at the $\mathrm{W}^{80}$ and $\mathrm{W}^{83}$ residues in the TSR-1 domain (Fig. 1A). Although the physiological functions of RPESP remain unclear, the Rspo family and certain proteins have been reported to be $C$-mannosylated in the TSR-1, and $C$-mannosylation of these proteins regulates their functions, including secretion and Wnt/ $\beta$-catenin signal-enhancing activity $(12,19)$. Therefore, $C$-mannosylation of RPESP may regulate its functions. To determine whether RPESP is $C$-mannosylated, the present study established an RPESP-overexpressing HT1080 cell line, HT1080-RPESP-MH cells (Fig. 1B). Although RPESP has a predicted $\mathrm{N}$-terminal signal peptide, the present study did not detect RPESP secretion in the conditioned medium in the HT1080-RPESP-MH cells (data not shown). Therefore, the present study purified recombinant RPESP protein from whole-cell lysates of HT1080-RPESP-MH cells for LC-MS analysis (Fig. 2A). The obtained recombinant RPESP was treated with trypsin and the resulting mixture of peptides was analyzed using the targeted MS/MS method. According to the inclusion list of three quadruple-protonated parent ions of un-mannosylated $(\mathrm{m} / \mathrm{z}, 797.09)$, mono-mannosylated $(\mathrm{m} / \mathrm{z}, 837.60)$ and di-mannosylated $(\mathrm{m} / \mathrm{z}, 878.11)$ ${ }^{69}$ ACPARPCFVGEWSPWSGCADQCKPTTR ${ }^{95}$ peptides, MS/MS spectra were obtained. The selected ion chromatograms of $\mathrm{y}_{5}$ ion of these parent ions were determined (Fig. 2B). Fig. 2B demonstrated that un- and mono-mannosylated peptides were not detected, which suggests that all RPESP 
A

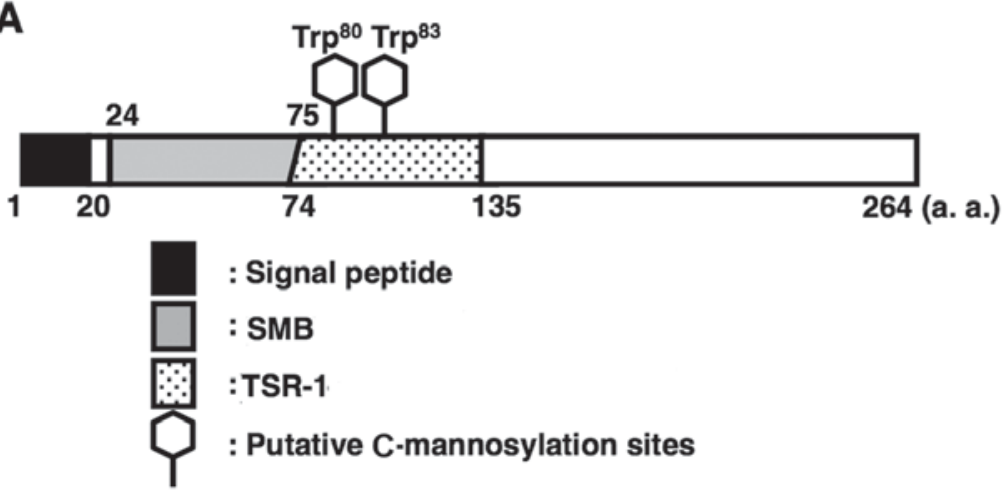

B

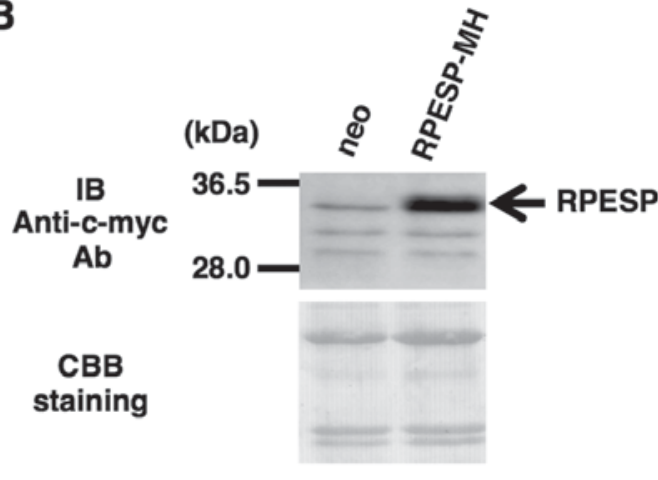

Figure 1. Establishment of an RPESP-overexpressing cell line. (A) Schematic diagram of human RPESP. RPESP has two possible $C$-mannosylation sites within TSR-1. A black box, gray box, dotted box and two hexagonal shapes denote the signal peptide, SMB, TSR-1 and the putative $C$-mannosylation sites, respectively. (B) Establishment of an RPESP-overexpressing cell line, HT1080-RPESP-MH. HT1080-neo and HT1080-RPESP-MH cells were lysed and each cell lysate was electrophoresed, and immunoblotted with anti-c-myc antibody. The membrane was stained by CBB solution following immunoblotting. RPESP, RPE-spondin; TSR-1, thrombospondin type-1 repeat; SMB, somatomedin B; CBB, Coomassie Brilliant Blue; a.a, amino acid; neo, HT1080 cells expressing the pCI-neo vector.

protein is $C$-mannosylated at $\mathrm{W}^{80}$, and $\mathrm{W}^{83}$. The MS/MS spectrum of the quadruple-charged di-mannosylated peptide ion $(m / z, 878.11)$ is presented in Fig. 2C. LC-MS/MS analysis of the peptide, modified by two mannose residues, revealed that the differences in the theoretical $\mathrm{m} / \mathrm{z}$ values for non-mannosylated tryptophan between $b_{5}-b_{11}$ and $y_{3}-y_{12}$ ions were not observed. This result indicates that modification occurs at the peptide ${ }^{80} \mathrm{WSPW}^{83}$. Glycosylation at a proline residue has not been reported. Furthermore, addition of hexose at a serine residue by $O$-glycosylation has previously been reported (29), including $O$-glucosylation of epidermal growth factor-like repeats and $O$-mannosylation of $\alpha$-dystroglycan; however, these modifications were site-specific, and RPESP did not satisfy the requirements (29). Additionally, the $\mathrm{W}^{80}$ and $\mathrm{W}^{83}$ residues met the requirements of the $C$-mannosylation consensus sequence $\mathrm{W}-\mathrm{X}-\mathrm{X}-\mathrm{W} / \mathrm{C}$, which suggests that RPESP may be $C$-mannosylated at $\mathrm{W}^{80}$ and $\mathrm{W}^{83}$.

Identification of DPY19L3 as the C-mannosyltransferase of RPESP at $W^{83}$. A previous report demonstrated that C.elegans dpy-19 was identified as a $C$-mannosyltransferase for TSR-1 (11), and that DPY19L3 catalyzes $C$-mannosylation of human Rspo1 at the $\mathrm{W}^{156}$ residue in human cells (12). Since $C$-mannosylation of RPESP occurred in TSR-1, the present study hypothesized that at least one of the human homologs (DPY19L1-L4) of $C$. elegans dpy-19 may be a $C$-mannosyltransferase of RPESP. In order to identify the $C$-mannosyltransferase(s) of RPESP, the present study performed gain-of-function experiments. Drosophila S2 cells have no $C$-mannosyltransferase activity $(11,30,31)$ but harbor dolichol-phosphate-mannose, which is the donor substrate for $C$-mannosylation. The present study transiently transfected human RPESP cDNA with the probable $C$-mannosyltransferase DPY19L1-L4 or empty vector (mock), respectively, into $\mathrm{S} 2$ cells. The expression of transfected DPY19L1-L4 mRNAs in S2 cells was confirmed by RT-sqPCR (Fig. 3A). Recombinant RPESP proteins were purified from each $\mathrm{S} 2$ cell lysate and analyzed using LC-MS. The obtained recombinant RPESP were aminoethylated, digested with trypsin and the resulting peptides were analyzed using the targeted MS/MS method. According to the inclusion list of three doubly protonated parent ions of un-, mono- and di-mannosylated ${ }^{76} \mathrm{FVGEWSPWSGC}{ }^{86}$ peptides, MS/MS spectra were obtained. Selected ion chromatograms of $\mathrm{y}_{5}$ ions of these parent ions were determined (Fig. 3A). Mono-mannosylated peptide was observed only when RPESP was produced in DPY19L3-expressing S2 cells; conversely, di-mannosylated peptide was not observed in any of the samples (Fig. 3A). These results suggested that human DPY19L3 catalyzes $C$-mannosylation of RPESP at a tryptophan residue. The MS/MS spectra of the doubly charged un- and mono-mannosylated peptide ion derived from DPY19L3-expressing S2 cells were presented (Fig. 3B). The $\mathrm{y}_{3}$ ion corresponded well in un- and mono-mannosylated peptides; however, $\mathrm{y}_{4}-\mathrm{y}_{6}$ ions were observed at an increased position of $m / z 162$ in mono-mannosylated peptide compared with the unmannosylated peptide (Fig. 3B). These results suggested that DPY19L3 may be the $C$-mannosyltransferase of RPESP at only the $\mathrm{W}^{83}$ residue.

Expression level of RPESP in human tumor cell lines. To examine the roles of RPESP in tumor malignancy, the present study analyzed RPESP mRNA expression levels using RT-sqPCR in a number of human tumor cell lines. Among 8 cell lines, the expression level of RPESP in HT29 cells was high; however, RPESP mRNA in other cell lines was undetectable under the assay conditions maintained (Fig. 4A). Since endogenous RPESP mRNA in HT29, a colon cancer cell line, was detected, the present study evaluated the expression levels of other human colon cancer cell lines. As presented in Fig. 4B, HT29, CW-2 and LoVo cells expressed RPESP mRNA, although COLO 205 and HCT116 did not. Therefore, it was suggested that RPESP may serve certain roles in tumorigenesis, particularly in colon cancer.

\section{Discussion}

The present study suggested that human RPESP may be $C$-mannosylated at $\mathrm{W}^{80}$ and $\mathrm{W}^{83}$. Previous studies have suggested that $C$-mannosylation has potential functions, including protein folding, stability, secretion and enzymatic 
A

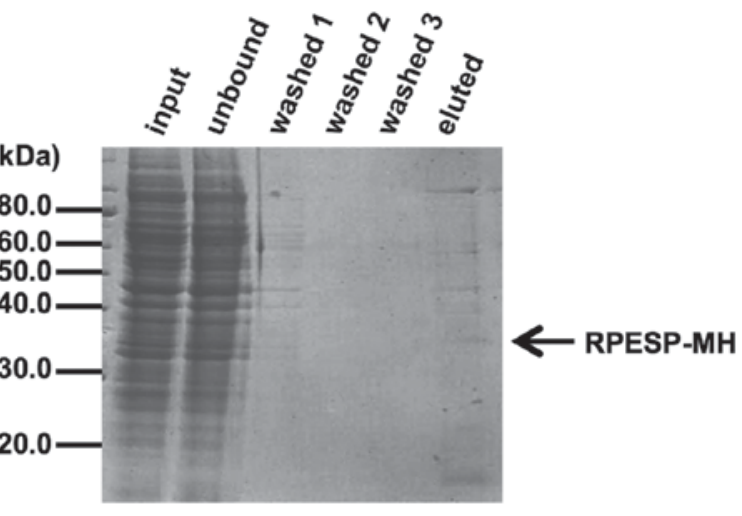

B
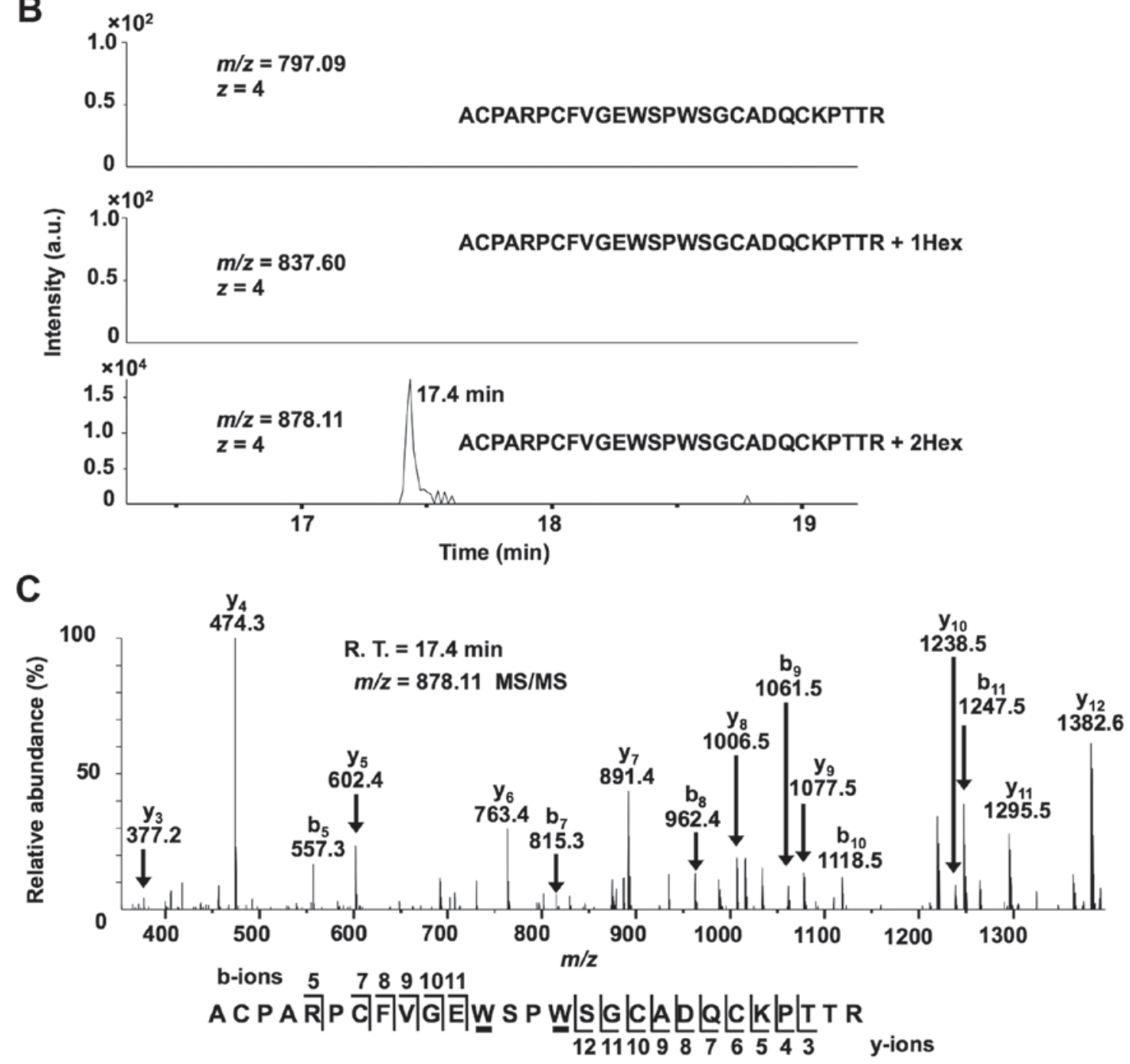

Figure 2. RPESP is $C$-mannosylated in cells. (A) Purification of recombinant RPESP-MH from whole-cell lysate of HT1080-RPESP-MH. HT1080-RPESP-MH cells were lysed and cell lysate was treated with ammonium sulfate. The precipitate between 30-60\% saturation of ammonium sulfate was dissolved in PBS (input) and recombinant RPESP-MH was purified using Ni-NTA agarose. These samples were electrophoresed and detected by CBB staining. (B and C) Determination of $C$-mannosylation sites within RPESP. The samples were digested with trypsin and the resulting peptides were analyzed using the targeted MS/MS method. According to the inclusion list of three quadruple-protonated parent ions of un-mannosylated $(\mathrm{m} / z$, 797.09), mono-mannosylated $(\mathrm{m} / z, 837.60)$ and di-mannosylated ${ }^{69}$ ACPARPCFVGEWSPWSGCADQCKPTTR ${ }^{95}$ peptides $(\mathrm{m} / \mathrm{z}, 878.11)$, MS/MS spectra were obtained. Selected ion chromatograms of $\mathrm{y}_{5}$ ion $(602.366 \pm 20 \mathrm{ppm})$ of these parent ions were determined (B). The MS/MS spectrum of the quadruple-charged di-mannosylated peptide ion $(\mathrm{m} / \mathrm{z}, 878.11)$ is presented $(\mathrm{C})$. The indicated $\mathrm{b}$ - and $\mathrm{y}$-series ions were detected as singly charged ions and $C$-mannosylation at the $\mathrm{W}^{80}$ and $\mathrm{W}^{83}$ residues of RPESP were suggested. $C$-mannosyltryptophans are underlined. RPESP, RPE-spondin; CBB, Coomassie Brilliant Blue; MS, mass spectrometry; Hex, hexose; R.T., retention time.

activity $(12,19,22,32,33)$. Certain TSR-1 superfamily proteins are reported to be $C$-mannosylated, particularly in Rspol and Rspo3; the modifications regulate their secretion and the agonistic activity of canonical Wnt signaling pathways $(12,19)$; however, the physiological functions of RPESP have not yet been investigated. In our preliminary experiment, 
A

FVGEWSPWSGC
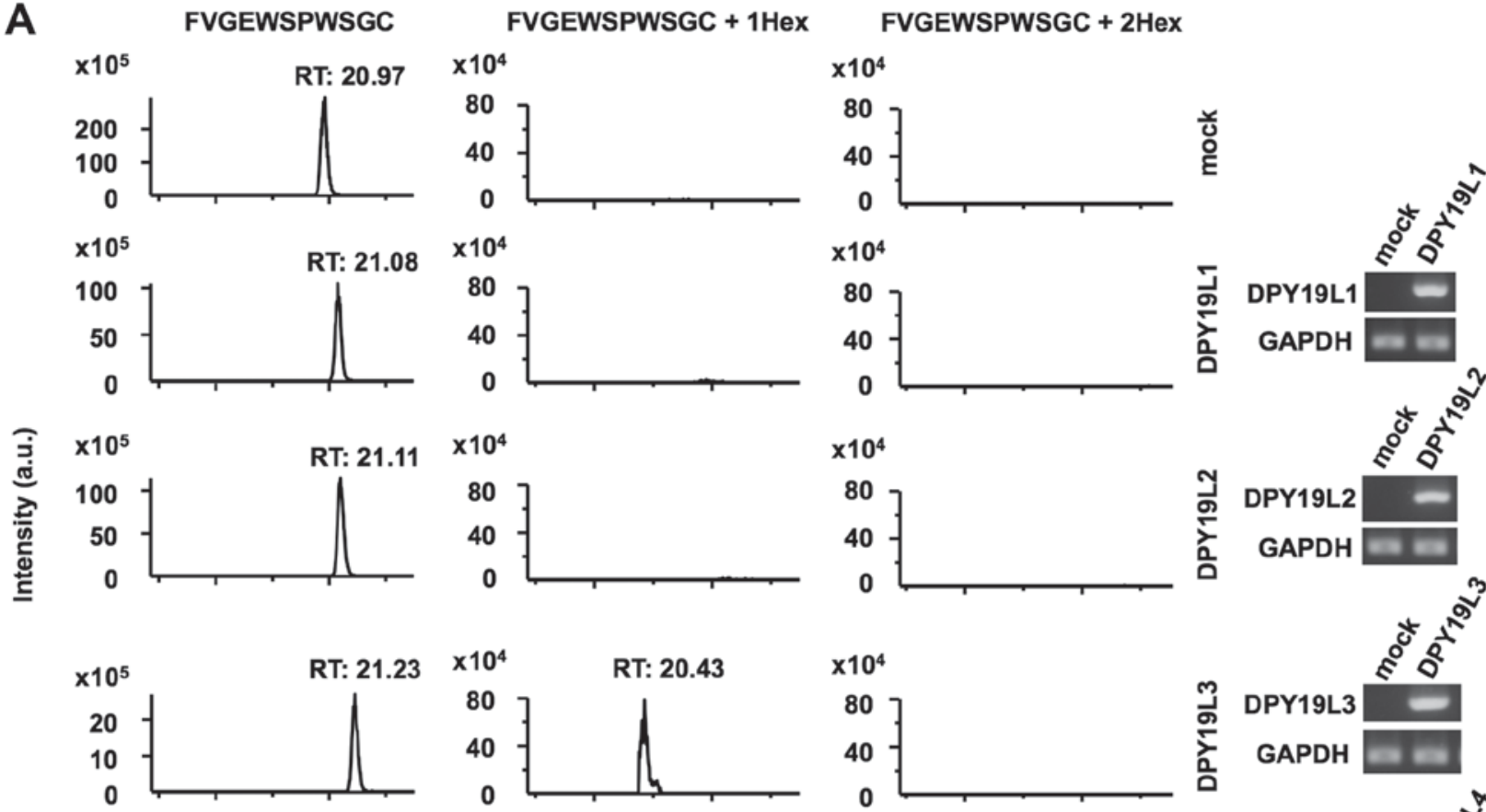

GAPDH $=0$
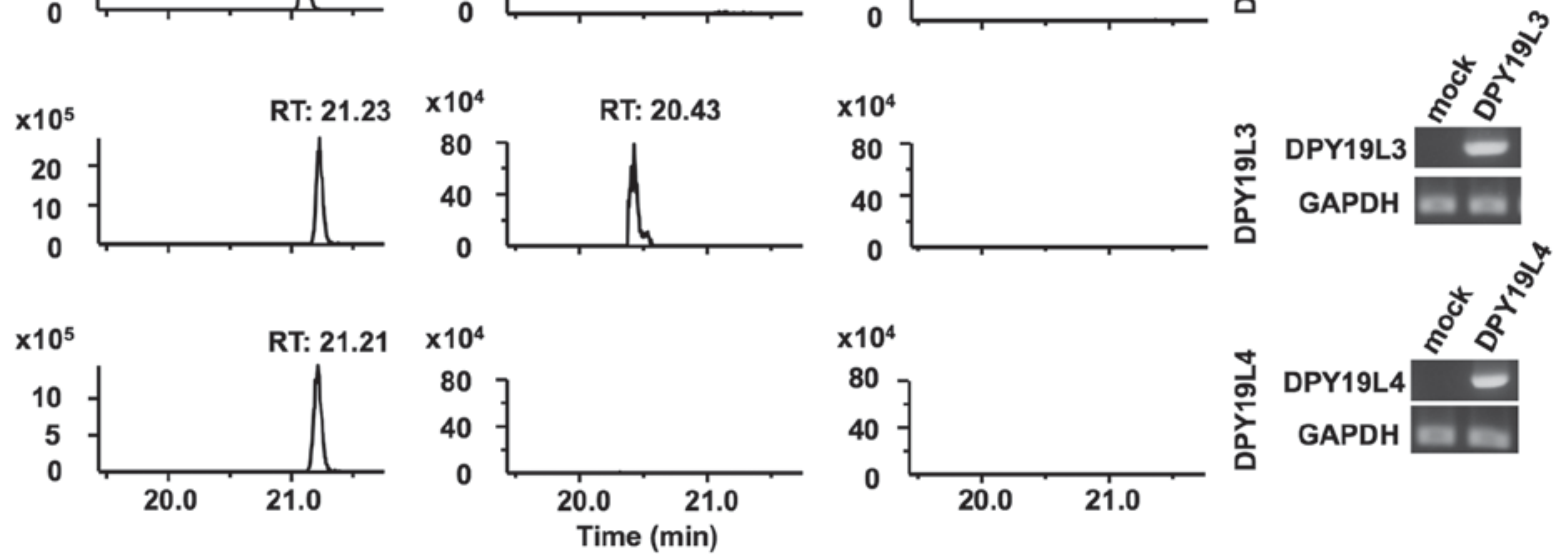

B

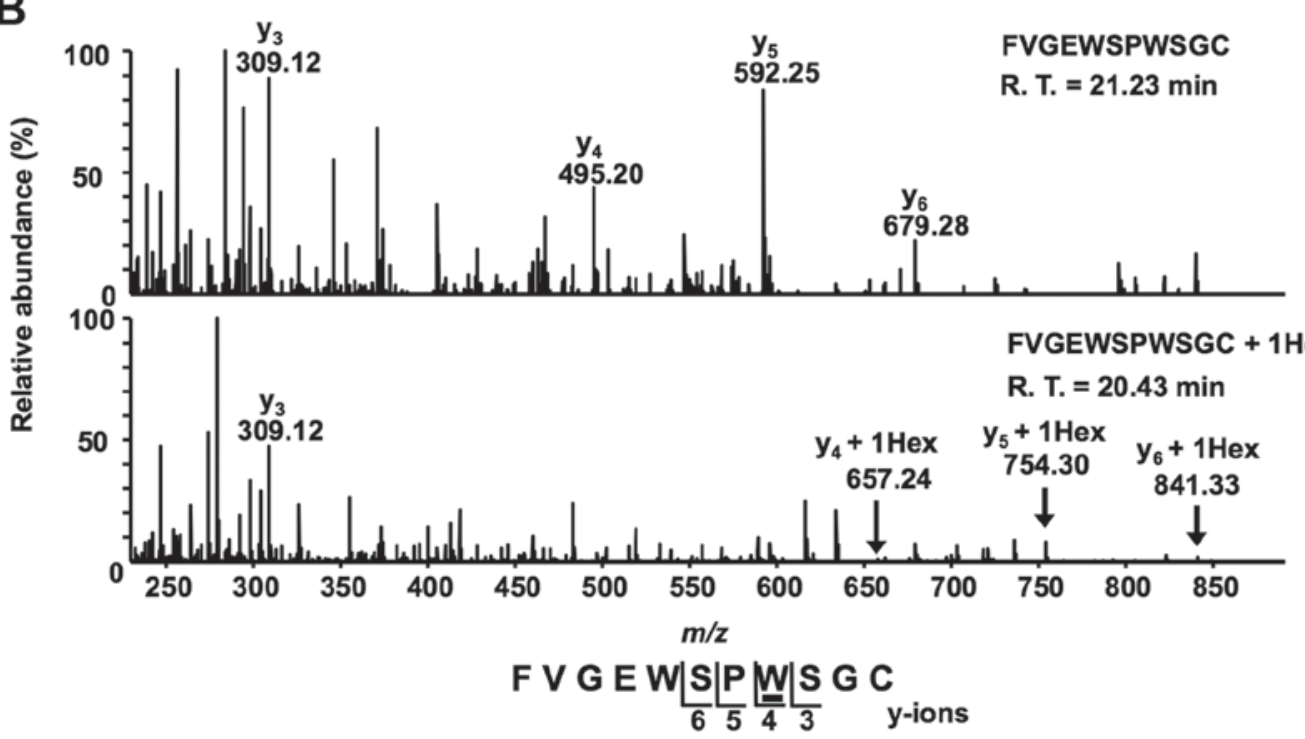

Figure 3. DPY19L3 is the $C$-mannosyltransferase of RPESP at only $\mathrm{W}^{83}$. (A and B) Identification of $C$-mannosyltransferase of RPESP. Human DPY19L1-L4 or empty vector (mock) and pMT-RPESP-MH were transiently transfected into Drosophila S2 cells and protein expression was induced using treatment with $700 \mu \mathrm{M} \mathrm{CuSO}_{4}$ for $48 \mathrm{~h}$. RPESP-MH protein was purified with Ni-NTA agarose. Following aminoethylation, the samples were digested with trypsin, and the resulting peptides were analyzed by targeted MS/MS method. According to the inclusion list of three doubly protonated parent ions of un-mannosylated $(\mathrm{m} / \mathrm{z}$, 649.28), mono-mannosylated $(\mathrm{m} / \mathrm{z}, 730.31)$ and di-mannosylated ${ }^{76} \mathrm{FVGEWSPWSGC}{ }^{86}$ peptides $(\mathrm{m} / \mathrm{z}, 811.34)$, MS/MS spectra were obtained. Selected ion chromatograms of $\mathrm{y}_{5}$ ion of these parent ions were determined (A, left panel). The expression of transfected DPY19L1-L4 mRNAs in S2 cells was confirmed by reverse transcription-semi-quantitative polymerase chain reaction (A, right panel). The MS/MS spectra of the doubly charged un- (B, upper panel) and mono- (B, lower panel) mannosylated peptide ion derived from DPY19L3-expressing S2 cells are presented. The indicated y-series ions were detected as singly charged ions and only the $\mathrm{W}^{83}$ residue of RPESP was $C$-mannosylated. $C$-mannosyltryptophan is underlined. DPY19L, dpy-19 like; MS, mass spectrometry; RPESP, RPE-spondin; Hex, hexose; R.T., retention time.

the present study investigated the mRNA expression level of RPESP among various types of cancer cell lines. RPESP was expressed in certain colon adenocarcinoma cell lines (HT29,
CW-2 and LoVo) but not in any other cancer cell line investigated, which suggests an importance of RPESP expression in colorectal cancer. Previously it was reported that RPESP 
A

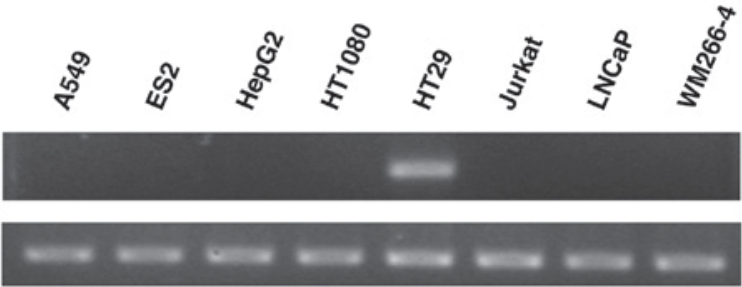

B

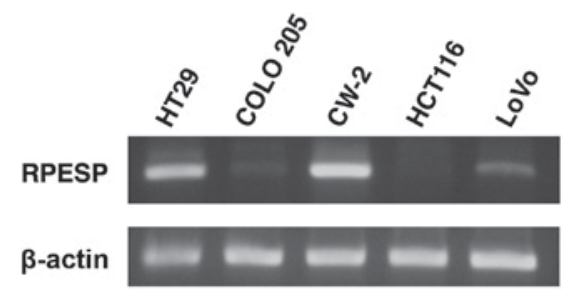

Figure 4. RPESP is expressed in certain colon cancer cell lines. (A) Expression of RPESP mRNA in human tumor cell lines. Total RNAs were isolated from A549 lung adenocarcinoma, ES2 ovarian cancer, HepG2 hepatoma, HT1080 fibrosarcoma, HT29 colon cancer, Jurkat leukemia, LNCaP prostate cancer and WM266-4 melanoma cells and RT-sqPCR analysis was performed (B) Expression of RPESP mRNA in human colon cancer cell lines. Total RNAs were isolated from human colon cancer cell lines, HT29, COLO 205, CW-2, HCT116 and LoVo, and RT-sqPCR analysis was performed. RT-sqPCR, reverse transcription-semi-quantitative polymerase chain reaction; RPESP, RPE-spondin.

exists in the aorta extracellular matrix (14); however, the physiological functions remain unclear. Considering RPESP is expressed in colon adenocarcinoma cell lines, RPESP may be involved in malignant alteration of cancer. As the present study was not able to elucidate the association between the physiological functions of RPESP or the role of $C$-mannosylation on RPESP and cancer, further studies are required.

A previous study demonstrated that $C$. elegans dpy-19 was a $C$-mannosyltransferase of TSR-1 (11). Based on this study, the present study investigated the human $C$-mannosyltransferase(s) of Rspo1, which has two $C$-mannosylation sites at $\mathrm{W}^{153}$ and $\mathrm{W}^{156}$, and identified humanDPY19L3, one of the homologs of C.elegans dpy-19, as a $C$-mannosyltransferase of Rspol at $\mathrm{W}^{156}(12)$. The present study also investigated the $C$-mannosyltransferase(s) of RPESP, which has two $C$-mannosylation sites at $\mathrm{W}^{80}$ and $\mathrm{W}^{83}$, and revealed that human RPESP was $C$-mannosylated at $\mathrm{W}^{83}$ by DPY19L3. DPY19L3, and not DPY19L1, DPY19L2 or DPY19L4, acted as a $C$-mannosyltransferase of RPESP at the $\mathrm{W}^{83}$ residue, and $C$-mannosylation of RPESP at $\mathrm{W}^{80}$ was not catalyzed by all DPY19 family proteins, suggesting the existence of other $C$-mannosyltransferase member(s) in human cells. Further studies are required in order to identify the novel $C$-mannosyltransferase of RPESP at $\mathrm{W}^{80}$.

In conclusion, the present study demonstrated that RPESP was $C$-mannosylated by DPY19L3 in human cells. Although the physiological functions of RPESP and the significance of its $C$-mannosylation remain unclear, our previous and present studies suggest that human DPY19 family members have substrate specificity, and that DPY19L3 may have a selective amino acid sequence for $C$-mannosylation. These studies may aid in furthering the understanding of DPY19L3-mediated $C$-mannosylation and RPESP functions in cancer.

\section{Acknowledgements}

The present study was supported in part by Grants-in-Aid for Scientific Research (B) (grant no. 24310167) and Japan Society for the Promotion of Science Fellowship (grant no. 254256).

\section{References}

1. Dwek RA, Butters TD, Platt FM and Zitzmann N: Targeting glycosylation as a therapeutic approach. Nat Rev Drug Discov 1: $65-75,2002$.

2. Simizu S, Ishida K, Wierzba MK and Osada H: Secretion of heparanase protein is regulated by glycosylation in human tumor cell lines. J Biol Chem 279: 2697-2703, 2004.

3. Simizu S, Takagi S, Tamura Y and Osada H: RECK-mediated suppression of tumor cell invasion is regulated by glycosylation in human tumor cell lines. Cancer Res 65: 7455-7461, 2005.

4. Furmanek A and Hofsteenge J: Protein C-mannosylation: Facts and questions. Acta Biochim Pol 47: 781-789, 2000.

5. Doucey MA, Hess D, Cacan R and Hofsteenge J: Protein $\mathrm{C}$-mannosylation is enzyme-catalysed and uses dolichylphosphate-mannose as a precursor. Mol Biol Cell 9: 291-300, 1998.

6. Krieg J, Hartmann S, Vicentini A, Gläsner W, Hess D and Hofsteenge J: Recognition signal for C-mannosylation of Trp-7 in RNase 2 consists of sequence Trp-x-x-Trp. Mol Biol Cell 9: 301-309, 1998

7. de Beer T, Vliegenthart JF, Löffler A and Hofsteenge J: The hexopyranosyl residue that is C-glycosidically linked to the side chain of tryptophan-7 in human RNase Us is alpha-mannopyranose. Biochemistry 34: 11785-11789, 1995.

8. Doucey MA, Hess D, Blommers MJ and Hofsteenge J: Recombinant human interleukin-12 is the second example of a C-mannosylated protein. Glycobiology 9: 435-441, 1999.

9. Hartmann S and Hofsteenge J: Properdin, the positive regulator of complement, is highly C-mannosylated. J Biol Chem 275: 28569-28574, 2000.

10. Li Y, Cao C, Jia W, Yu L, Mo M, Wang Q, Huang Y, Lim JM, Ishihara M, Wells L, et al: Structure of the F-spondin domain of mindin, an integrin ligand and pattern recognition molecule. EMBO J 28: 286-297, 2009.

11. Buettner FF, Ashikov A, Tiemann B, Lehle L and Bakker H: C. elegans DPY-19 is a C-mannosyltransferase glycosylating thrombospondin repeats. Mol Cell 50: 295-302, 2013.

12. Niwa Y, Suzuki T, Dohmae N and Simizu S: Identification of DPY19L3 as the C-mannosyltransferase of R-spondin1 in human cells. Mol Biol Cell 27: 744-756, 2016.

13. Schulz HL, Rahman FA, Fadl El Moula FM, Stojic J, Gehrig A and Weber BH: Identifying differentially expressed genes in the mammalian retina and the retinal pigment epithelium by suppression subtractive hybridization. Cytogenet Genome Res 106: 74-81, 2004.

14. Didangelos A, Yin X, Mandal K, Baumert M, Jahangiri M and Mayr M: Proteomics characterization of extracellular space components in the human aorta. Mol Cell Proteomics 9: 2048-2062, 2010.

15. Zhou A, Huntington JA, Pannu NS, Carrell RW and Read RJ: How vitronectin binds PAI-1 to modulate fibrinolysis and cell migration. Nat Struct Biol 10: 541-544, 2003.

16. Kamikubo Y, De Guzman R, Kroon G, Curriden S, Neels JG, Churchill MJ, Dawson P, Ołdziej S, Jagielska A, Scheraga HA, et al: Disulfide bonding arrangements in active forms of the somatomedin B domain of human vitronectin. Biochemistry 43: 6519-6534, 2004.

17. Mayasundari A, Whittemore NA, Serpersu EH and Peterson CB: The solution structure of the $\mathrm{N}$-terminal domain of human vitronectin: Proximal sites that regulate fibrinolysis and cell migration. J Biol Chem 279: 29359-29366, 2004.

18. Kato K, Nishimasu H, Okudaira S, Mihara E, Ishitani R, Takagi J, Aoki J and Nureki O: Crystal structure of Enpp1, an extracellular glycoprotein involved in bone mineralization and insulin signaling. Proc Natl Acad Sci USA 109: 16876-16881, 2012.

19. Fujiwara M, Kato S, Niwa Y, Suzuki T, Tsuchiya M, Sasazawa Y, Dohmae N and Simizu S: C-mannosylation of R-spondin3 regulates its secretion and activity of $\mathrm{Wnt} / \beta$-catenin signaling in cells. FEBS Lett 590: 2639-2649, 2016. 
20. Iwaki T and Castellino FJ: A single plasmid transfection that offers a significant advantage associated with puromycin selection in Drosophila Schneider S2 cells expressing heterologous proteins. Cytotechnology 57: 45-49, 2008.

21. Niwa Y, Suzuki T, Dohmae N, Umezawa K and Simizu S: Determination of cathepsin V activity and intracellular trafficking by N-glycosylation. FEBS Lett 586: 3601-3607, 2012.

22. Goto Y, Niwa Y, Suzuki T, Dohmae N, Umezawa K and Simizu S: C-mannosylation of human hyaluronidase 1: Possible roles for secretion and enzymatic activity. Int J Oncol 45: 344-350, 2014.

23. Goto Y, Niwa Y, Suzuki T, Uematsu S, Dohmae N and Simizu S $\mathrm{N}$-glycosylation is required for secretion and enzymatic activity of human hyaluronidase1. FEBS Open Bio 4: 554-559, 2014.

24. Simizu S, Suzuki T, Muroi M, Lai NS, Takagi S, Dohmae N and Osada H: Involvement of disulfide bond formation in the activation of heparanase. Cancer Res 67: 7841-7849, 2007.

25. Simizu S, Umezawa K, Takada M, Arber N and Imoto $M$ Induction of hydrogen peroxide production and Bax expression by caspase-3(-like) proteases in tyrosine kinase inhibitor-induced apoptosis in human small cell lung carcinoma cells. Exp Cell Res 238: 197-203, 1998.

26. Miyazaki S, Sasazawa Y,Mogi T, Suzuki T, Yoshida K, Dohmae N, Takao K and Simizu S: Identification of seco-clavilactone B as a novel small-molecule actin polymerization inhibitor. FEBS Lett 590: 1163-1173, 2016.
27. Welinder $\mathrm{C}$ and Ekblad L: Coomassie staining as loading control in western blot analysis. J Proteome Res 10: 1416-1419, 2011.

28. Michalski A, Damoc E, Hauschild JP, Lange O, Wieghaus A, Makarov A, Nagaraj N, Cox J, Mann M and Horning S: Mass spectrometry-based proteomics using $\mathrm{Q}$ exactive, a high-performance benchtop quadrupole Orbitrap mass spectrometer. Mol Cell Proteomics 10: M111.011015, 2011.

29. Moremen KW, Tiemeyer M and Nairn AV: Vertebrate protein glycosylation: Diversity, synthesis and function. Nat Rev Mol Cell Biol 13: 448-462, 2012.

30. Krieg J, Gläsner W, Vicentini A, Doucey MA, Löffler A, Hess D and Hofsteenge J: C-mannosylation of human RNase 2 is an intracellular process performed by a variety of cultured cells. J Biol Chem 272: 26687-26692, 1997.

31. Hofsteenge J, Huwiler KG, Macek B, Hess D, Lawler J, Mosher DF and Peter-Katalinic J: C-mannosylation and O-fucosylation of the thrombospondin type 1 module. J Biol Chem 276: 6485-6498, 2001.

32. Perez-Vilar J, Randell SH and Boucher RC: C-mannosylation of MUC5AC and MUC5B Cys subdomains. Glycobiology 14: 325-337, 2004

33. Sasazawa Y, Sato N, Suzuki T, Dohmae N and Simizu S: $\mathrm{C}$-mannosylation of thrombopoietin receptor (c-Mpl) regulates thrombopoietin-dependent JAK-STAT signaling. Biochem Biophys Res Commun 468: 262-268, 2015. 